\title{
Sara Brandellero; Derek Pardue e Georg Wink (Orgs.) - Living (il)legalities in Brazil. Londres: Editora Routledge, 2020
}

\author{
Juliana Santini*
}

No momento em que este texto é escrito, o Brasil já ultrapassa duzentos mil mortos ao longo da pandemia provocada pelo vírus Sars-Cov2 ${ }^{1}$ e a cidade de Manaus enfrenta o esgotamento dos estoques de oxigênio na rede de saúde, com pessoas mortas por sufocamento nos leitos dos hospitais. A despeito desse quadro, o presidente Jair Messias Bolsonaro e o Ministério da Saúde divulgam publicamente o sucesso do governo brasileiro no combate ao coronavírus e, embora assumam a existência de um colapso, culpabilizam estado, prefeitura e corpo médico por não utilizarem o que se tem chamado de "tratamento precoce" para a doença (MAтtoso, 2021), um coquetel já anunciado como inútil por pesquisas científicas realizadas no mundo todo.

A disparidade entre a realidade empírica e o discurso governamental encontra eco em notícias falsas espalhadas em grupos de WhatsApp, redes sociais e sites que trabalham a favor do bolsonarismo, enquanto dezenas de pedidos de impeachment do presidente por crimes de responsabilidade e apologia à tortura permanecem sem andamento. O complexo entrelaçamento das relações políticas brasileiras coloca em xeque o princípio da legalidade das práticas institucionais e projeta sucessivos questionamentos sobre o impacto dessas práticas no cotidiano, sempre à mercê do desmantelamento de políticas sociais e repetidos movimentos de criminalização das minorias.

Com um conjunto de análises múltiplas das manobras que conduziram o país a esse estado de coisas, o livro Living (il)legalities in Brazil: practices, narratives and institutions in a country on the edge, apresenta onze ensaios reunidos por Sara Brandellero, Derek Pardue e Georg Wink, publicados pela editora Routledge no ano de 2020. Abarcando um contexto mais amplo, anterior à pandemia, os textos colocam em cena não apenas as fronteiras entre legalidade e ilegalidade no cenário político e cultural das últimas décadas no Brasil, mas também as práticas sociais

* Livre-docente em Literatura Brasileira, professora do Departamento de Linguística, Literatura e Letras Clássicas e do Programa de Pós-Graduação em Estudos Literários da Universidade Estadual de São Paulo, Campus Araraquara, SP, Brasil. E-mail: juliana.santini@unesp.br.

1 Conforme dados oficiais do Ministério da Saúde disponíveis em https://covid.saude.gov.br/. 
e discursivas que produzem e sustentam o esfumaçamento dessas instâncias em favor de processos da manutenção do poder, da desigualdade e da exploração.

O volume articula uma série de reflexões política, etnográfica e sociológica à crítica da cultura, construindo um largo espectro de observação que se divide em duas partes: na primeira, intitulada "Producing (il)legalities, cinco textos ${ }^{2}$ focalizam a política brasileira, que produz discursos e práticas de desmonte da democracia e de mascaramento do autoritarismo sob o verniz da lei, além das práticas sociais que, no cotidiano das cidades, determinam a legalidade e a ilegalidade da circulação de refugiados ${ }^{3}$ ou as negociações que envolvem medidas econômicas de comércio e circulação de bens e produtos sob o status da formalidade e da informalidade. ${ }^{4}$

Na segunda parte, Representing (il)legalities, são seis os ensaios que partem da representação cultural em que o legal e o ilegal aparecem de maneira fluida quando postos a serviço das diferenças de classe ou, ainda, no modo como a atribuição da ilegalidade funciona enquanto tentativa de anulação da resistência política.

A apreciação do volume aqui apresentada não pretende fornecer um resumo de cada um dos ensaios que compõem o livro, o que, se por um lado, criaria uma perspectiva panorâmica da multiplicidade de temas abordados, por outro, correria o risco de se perder na generalidade e no descritivismo. Em uma tentativa de síntese, o que se pretende desenvolver é a hipótese de que, lidos em conjunto, os textos oferecem elementos para a observação da existência de uma dialética da ilegalidade em determinadas práticas sócio-político-culturais do Brasil contemporâneo, em que se verifica a construção e a representação de espaços de marginalização por meio de normas flutuantes ou, se assim se preferir, de legalidades relativas cujo agenciamento depende da posição discursiva, hierárquica ou ideológica daqueles que detêm o poder.

João César de Castro Rocha, em texto de 2006, propõe a revisão do modelo interpretativo da sociedade brasileira sistematizado por Antonio Candido (1970) em sua conhecida análise do romance Memórias de um sargento de milícias, opondo a dialética da malandragem à configuração de uma "dialética da marginalidade" que escancara o uso da violência como instrumento que substitui a cordialidade do esquema original:

[...] a "dialética da malandragem" está sendo parcialmente substituída ou, para dizer o mínimo, diretamente desafiada pela "dialética da marginalidade" a qual está principalmente fundada no princípio da superação das desigualdades sociais através do confronto direto em vez da

\footnotetext{
2 Como se trata de uma coletânea de ensaios com múltipla autoria, os dados bibliográficos de cada texto em particular serão informados, quando for o caso, de modo reduzido. A citação do volume completo serve como referência para a resenha como um todo.

3 Machado, Igor; Pardue, Derek, 2020, p. 36-51.

4 Hirata, Daniel, 2020, p. 22-34.
} 
conciliação, através da exposição da violência em vez de sua ocultação (RochA, 2006, p.36).

Diante dos termos propostos pelo autor, o esboço de uma dialética da ilegalidade nas páginas de Living (il)legalities in Brazil aponta para o funcionamento de uma dinâmica paralela, em que cordialidade ou violência não fazem parte dos pactos estabelecidos, sendo eles muito menos explícitos do que a violência direta ou muito mais danosos do que a malandragem conciliadora. O primeiro termo dessa dinâmica se localiza na prática do lawfare, uso do aparato jurídico como forma de criminalizar ou destruir publicamente a imagem daqueles que defendem as minorias ou são vistos como detratores pelo poder hegemônico. Nesse caso, a fragilidade da democracia brasileira se revela, por exemplo, ao longo de todo o processo de destituição da presidenta Dilma Rousseff e nas sucessivas manobras legais que impediram o ex-presidente Lula de concorrer às eleições presidenciais em 2018.

Se o uso da justiça como prática que transforma a legalidade em instrumento de inversão dos valores democráticos se construiu a partir de um grande espetáculo midiático na ascensão de um perigoso instrumento de manipulação da opinião pública e da criação de uma máscara democrática que esconde sob seu verniz o autoritarismo e o conservadorismo, unidos em favor da instauração de um novo fascismo, não é menos verdade que, cotidianamente, o lawfare alia-se a diferentes instituições e a uma batalha discursiva que borra os limites entre o legal e o ilegal. ${ }^{5}$ Sob esse aspecto, a manipulação da verdade por meio da lei - ou sob a proteção dela - atua em um jogo perverso de construção de "verdades" aceitas coletivamente e disseminadas em massa.

Aqui, lawfare e fake news aparecem como expressões não traduzidas em sua utilização na Língua Portuguesa e pouco compreendidas pela população em geral, que muitas vezes reconhece como falsa ou distorcida a informação que tem em mãos, mas prefere partilhá-la porque atende a suas conviç̧ões de que o mal precisa ser extirpado. Chega-se a um ponto em que o primeiro termo constituinte do que se está chamando de dialética da ilegalidade no Brasil contemporâneo se desenha na atuação concomitante de duas práticas que operam como modos de intencionalmente tornar indistinguíveis o legal e o ilegal: o paradoxal uso da lei como forma de criminalização de adversários políticos ou figuras públicas e a consequente aniquilação de sua reputação; a disseminação de notícias falsas (não seria a manutenção do termo em inglês uma forma de torná-lo inacessível?) e discursos de ódio baseados em padrões de comportamento construídos em torno de valores conservadores, autoritariamente impostos por instituições socialmente influentes que auxiliam na determinação de quem permanecerá às margens da democracia.

O desdobramento dessa articulação conduz ao segundo elemento em análise na constituição da dialética da ilegalidade: práticas sociais, discursos e negociações

5 Deninison, Stephanie, 2020, p.117-130. 
entre poderes e agentes do poder que determinam o que é ilegal e para quem, resultando na criminalização de grupos minoritários, como imigrantes, negros, homossexuais, transgêneros, mulheres, habitantes das periferias ou sujeitos que definam e pratiquem sua identidade fora do padrão estabelecido como normal, sempre claramente alinhado ao domínio hegemônico do conservadorismo. A análise feita por Alexander S. Dent (2020 $)^{6}$ sobre a perseguição aos punks no Brasil nos últimos anos da ditadura militar e ao longo do processo de abertura política deixa claros alguns dos operadores utilizados na forja da ilegalidade em torno de um grupo que foi perseguido porque identificado a práticas sexuais "indecorosas", modos de se vestir "bizarros" e, porque importado, "comunista" e "antinacionalista".

E não se pode dizer que esses operadores tenham saído de cena, pelo contrário, o emparelhamento de posicionamentos políticos à esquerda e de defensores da implementação de políticas sociais a um comunismo anacrônico, distorcido e criminalizado tem se tornado cada vez mais forte desde a ascensão de Bolsonaro. Escancara-se, nesse sentido, a ligação entre a criminalização e a tentativa de dominação política e econômica que sustenta o discurso da ilegalidade que, muitas vezes, não corresponde ao que a interpretação da lei aponta como ilegal. A cena de $O$ som ao redor, filme de Kleber Mendonça Filho, analisada por Sara Brandellero (2020, p. 138), ${ }^{7}$ é emblemática da representação dessa fluidez - já que o que é legal para uns pode não ser para outros: na narrativa, o personagem que representa o poder das oligarquias na metrópole nada ao lado de uma placa que adverte sobre a presença de banhistas no mar, funcionando como uma metáfora de tudo que cabe sob sua propriedade e domínio, e revelando, inclusive, que compete a determinada classe decidir se submeter ou não à norma.

As negociações que fazem do jeitinho brasileiro o trampolim para que o malandro flutue entre a ordem e a desordem no paradigma de interpretação de Antonio Candido (1970) e em futuras leituras da formação social brasileira ${ }^{8}$ aparecem, nas relações entre legalidade e ilegalidade, dificultadas pelo modo como se dá a produção de discursos e os processos de deslegitimação das minorias. Nesse caso, a violência é, muitas vezes, a voz agônica da periferia no interior de um conjunto de práticas que não justificam o crime, mas deixam evidente como ele surge na dinâmica de uma lógica de opressão. As múltiplas perspectivas de análise do volume Living (il)legalities in Brazil problematizam a cultura brasileira e seus modos de representação da realidade nesse contexto, não abrindo mão da observação da própria realidade, o que amplia o espectro e permite a construção de uma teia em que prática e discurso se complexificam. E essa crítica se mostra cada vez mais neces-

\footnotetext{
Dent, Alexander, 2020, p. 89-101.

BRANDELLERo, Sara, 202O, p. 131-143.

Sobre a definição histórica da noção de "jeitinho" e sua construção discursiva, ver: WINK, Georg, 2020, p.52-70.
} 
sária conforme segue a panaceia de um poder que oprime, discrimina e deixa seus cidadãos morrerem enquanto segue afirmando que não tem nada a ver com isso. ${ }^{9}$

\section{Referências}

Brandellero, Sara; Pardue, Derek; Wink, Georg. (Orgs.). Living (il)legalities in Brazil: practices, narratives and institutions in a country on the edge. Londres: Routledge, 2020 .

CAndido, Antonio. Dialética da malandragem (Caracterização das Memórias de um sargento de milícias). Revista do Instituto de Estudos Brasileiros, São Paulo, n.8, p.67-89, 1970. Disponível em: https://www.revistas.usp.br/rieb/article/view/ 69638/72263. Acesso em: 10/01/2021.

Chaib, Julia; Carvalho, Daniel. 'E daí? Lamento, quer que eu faça o quê?', diz Bolsonaro sobre recorde de mortos por coronavírus. Folha de São Paulo. São Paulo, 28 abr. 2020. Disponível em: https://www1.folha.uol.com.br/equilibrioesaude/ 2020/o4/e-dai-lamento-quer-que-eu-faca-o-que-diz-bolsonaro-sobre-recordede-mortos-por-coronavirus.shtml. Acesso em: 10 jan. 2021.

Matroso, Camila. Ministério da Saúde pressiona Manaus e diz ser 'inadmissível' não usar cloroquina contra Covid-19. Folha de São Paulo. São Paulo, 12 jan. 2021. Disponível em: https://www1.folha.uol.com.br/colunas/painel/2021/ o1/ministerio-da-saude-pressiona-manaus-e-diz-ser-inadmissivel-nao-usarcloroquina-contra-covid-19.shtml?origin=folha. Acesso em: 12/01/2021.

RochA, João Cesar de Castro. A guerra de relatos no Brasil contemporâneo. Ou: a “dialética da marginalidade". Letras, Santa Maria, n.32, p.23-70, 2006. Disponível em: https://periodicos.ufsm.br/letras/article/view/11909. Acesso em: 10/o1/2021.

Recebido em 19 de janeiro de 2021.

Aprovado em 15 de junho de 2021.

9 Em abril de 2020, quando o Brasil ainda registrava número diário de mortos inferior a 500 pessoas, Jair Bolsonaro respondeu, em entrevista, quando foi perguntado sobre medidas para conter a pandemia: "E daí? Lamento, quer que eu faça o quê?" (Chaib; CARvalho, 2020). 